\title{
NATIONALLY HOSTED TAX INTERVENTION: EXPLORING SOUTH AFRICAN STUDENTS' PERCEPTIONS OF ITS USEFULNESS TO DEVELOP PERVASIVE SKILLS
}

\author{
H. A. Viviers* \\ School of Accounting Sciences \\ e-mail: herman.viviers@nwu.ac.za

\section{G. M. Reitsma*} \\ Centre for Health Professions Education \\ e-mail: gerda.reitsma@nwu.ac.za \\ *North-West University (Potchefstroom campus) \\ Potchefstroom, South Africa
}

\section{J. P. Fouche}

School of Accounting Sciences

North-West University (Vaal Triangle campus)

Vanderbijlpark, South Africa

e-mail: jaco.fouche@nwu.ac.za

\section{ABSTRACT}

The article explores the usefulness of a nationally hosted tax intervention presented to tax students from various South African universities to develop pervasive skills. In response to the call from professional bodies and employers to develop pervasive skills, the design of the intervention was aimed at affording students the opportunity in which they can apply and be exposed to the pervasive skills development. The article is unique in that it determines, based on the perceptions of a wide coverage of South African tax students, the usefulness of a one-of-a-kind tax-related intervention. Quantitative data was gathered through an action research process using questionnaires to evaluate the usefulness of the tax intervention in exposing students to pervasive skills and in encouraging them to apply it. Overall, the intervention was perceived as an effective teaching tool and tax students recommended it as a positive contributor in developing their pervasive skills as part of higher education and training.

Keywords: accounting education, action research, pervasive skills, skills development, South Africa, tax intervention, tax students

\section{INTRODUCTION}

Internationally employers call for graduates who are capable of applying their discipline- 
specific knowledge in the workplace (Jackson and Chapman 2012, 95). In response to the latter, professional accounting bodies are globally extending their technical knowledge-based accreditation criteria for registration as professional accountants to also include the development of pervasive skills and competencies (Steenkamp 2012, 482; Strauss-Keevy 2014). Pervasive skills (also generally referred to in the literature as "soft” or "generic" skills) encapsulates cognitive skills known to enhance graduate work-readiness (Jackson, Sibson and Riebe 2013, 7). Moreover, students perceive the inclusion of pervasive skills development as a crucial component of their higher education and training to make them more employable (Ramlall and Ramlall 2014).

Accounting education providers at the higher education level who are serious about better preparing their graduates for the formal workplace should take cognisance of the dire need for the development of pervasive skills and competencies (Bennett 2002). Although pervasive skills development initiatives have been mainly applied and researched at the higher education level in the subject areas of financial accounting (Stainbank 2009; Van der Merwe 2013), management accounting (Rudman and Kruger-van Renen 2014) and auditing (Rudman and Terblanche 2011; De Villiers and Fouché 2015), a gap is identified in the South African accounting educational domain for developing pervasive skills within the subject area of taxation.

A limited number of South African universities offer mainstream tax-focused degree programmes.

Taxation generally only constitutes a core module which underpins degree programmes that are mainly accounting-related. Hence, the majority of South African tax students are commonly enrolled for accounting degree programmes that are accredited by either international professional accounting bodies such as the Chartered Institute of Management Accountants (CIMA), the Chartered Global Management Accountant (CGMA), and the Association of Chartered Certified Accountants (ACCA), or local professional accounting bodies such as the South African Institute of Chartered Accountants (SAICA), the South African Institute of Tax Professionals (SAIT), and the South African Institute of Professional Accountants (SAIPA). The fact that the main objective of tax students studying one of the latter mentioned accounting degree programmes is to obtain a professional designation of either: CIMA; CGMA; ACCA; CA(SA); AGA(SA) or SAIPA, further highlights the importance of tax educators and trainers to be aware of accommodating towards the integration of the pervasive skills development demands required by these professional bodies as part of their higher education tax curricula (Strauss-Keevy 2014; 2015).

The aforementioned discussion reiterates the dire need to create new and innovative 
interventions that will expose and encourage students to apply and develop pervasive skills in a holistic manner (Ballantine and McCourt Larres 2009; Kermis and Kermis 2010, 5).

\section{RESEARCH OBJECTIVE AND CONTRIBUTION}

This research article was conducted with the main objective of evaluating the usefulness of a tax-related intervention to develop pervasive skills presented on a national level (within two regions) to tax students from various South African universities who attended the regional Tax Student Conferences hosted by SAIT. Based on student perceptions, the article endeavoured to answer the following research questions:

- Which pervasive skills did tax students apply during participation in the tax intervention?

- Which pervasive skills did the tax intervention expose tax students to?

- What were the main perceived benefits derived from participation in the tax intervention?

- What were the main perceived constraints of the tax intervention?

This article is unique in that it reports on a newly designed innovative tax-related intervention regarded to be the only one of its kind to be presented on a national level in South Africa focusing on pervasive skills development at the higher education level. In addition, based on a review of the literature it was found that no similar evaluation had already been conducted between tax students of different South African universities accredited with various professional bodies. The results might have far-reaching potential with a multi-disciplinary impact as pervasive skills are not subject specific (Barrie 2004). Hence, the findings could benefit pervasive skills development within any domain of knowledge as the content of the intervention under review could be easily exchanged by any other disciplinal information. The research contributes to the body of knowledge on pervasive skills development as part of higher education accounting curricula, and more specifically the field of taxation. The results serve as a valuable platform for accounting educators and trainers, including professional bodies and employers, in the design of innovative interventions to enhance and contribute towards pervasive skills development as part of higher education and training.

The rest of the article is structured as follows: Literature is reviewed to ascertain what the pervasive skills entail that are required by both international and local professional bodies. The latter will shed light upon the pervasive skills that need to be incorporated within the various accounting degree programmes that South African tax students are enrolled for, in order for these programmes to adhere to accreditation requirements of these bodies. In addition, literature 
on the application of teaching methods and strategies that support pervasive skills development are also reviewed. Hereafter, the development and design of the nationally hosted tax intervention are described and the research methodology is explained. This is followed by a report on the empirical findings relating to the intervention's success to expose tax students to pervasive skills and to encourage them to apply it. The last section summarises the key findings where conclusions, recommendations and suggestions for further research are made and the limitations of the study are stated.

\section{LITERATURE REVIEW}

\section{Pervasive skills required by international and local professional accounting bodies}

Competency frameworks are designed by professional bodies to assist the academic providers and future employers of their upcoming members to comprehend the desired knowledge, skills and competencies required for professional registration with such bodies. Competencies are viewed as the bridge between higher education and employment (CGMA 2014). SAICA (2016) identifies pervasive skills in three categories: (i) Professional Skills, (ii) Personal Attributes, and (iii) Ethical Behaviour and Professionalism. In addition to technical, organisational and business knowledge and skills, CIMA (2015) also requires of candidates to possess (i) People skills, and (ii) Leadership skills. The four major competencies required under the CGMA designation, jointly created by two international accounting bodies, namely CIMA and AICPA (Association of International Certified Professional Accountants), includes: (i) People skills and (ii) Leadership skills both resorting under soft (pervasive) skills; as well as (iii) Technical skills and (iv) Business skills both resonating under hard (technical) skills (CGMA 2014). ACCA (2015) requires competencies on three cognitive levels, namely: (i) the Professional level; (ii) the Knowledge level; and (iii) the Skills level as listed in the ACCA P6 Advanced Taxation South Africa (ZAF) syllabus and study guide.

Drawn from the descriptions of the required skills encapsulated within the competency frameworks of the various professional accounting bodies, it is concluded that students are required to develop the following pervasive skills: communication (verbal, listen, writing); critical thinking; ethical awareness; influencing others; leadership; problem solving; professionalism; team work; time management and strategy.

\section{Teaching methods and strategies to develop pervasive skills}

Despite the widely advocated and prevailing need to integrate soft skills development with 
higher education accounting curricula (Gammie, Gammie and Cargill 2002; Hassall et al. 2005; Ballantine and McCourt Larres 2009) studies are still not clear on the manners in which to effectively attain it (De Villiers 2010). Pervasive skills are believed to be developed through the application of experiential learning theory (Dewey 1938) combined with enhanced student engagement (Kolb and Kolb 2005). According to Fouché (2013), pervasive skills development is promoted by applying a wide range of active learning methods embodied by a learner-centred approach where students are encouraged to be actively involved during the entire learning process. Active learning methods include interactive learning and experience-based methods (interventions incorporating case studies, field experiences, games, role-plays and simulations), problem-based learning, cooperative learning and project-based learning. Moreover, StraussKeevy (2015) suggests that higher education should be sensitised in offering students opportunities in which they can actively participate in practical and collaborative learning experiences whereby real-world working environments are replicated. Experiential learning is beneficial in that it yields more motivated learners (Burns and Gentry 1998), is perceived to be more effective compared to traditional learning (Yan 1999), better supports effective management and decision-making skills and enhances professional and life-long learning through self-regulation and reflection (Hannon, McBride and Burns 2004). Hence, the next section describes the tax intervention that was developed whereby numerous active and experiential learning methods were combined and applied in an attempt to expose tax students to the development of pervasive skills required by professional accounting bodies.

\section{DEVELOPMENT AND DESIGN OF THE TAX INTERVENTION}

In response to the call from professional bodies and industry to expose students to pervasive skills development at the higher education level (as motivated under the Introduction section), the authors were granted approval by SAIT, the professional body for tax professionals in South Africa, to design and present a tax-related intervention to the tax students attending their annual regional (southern and northern) tax student conferences. The main design of the intervention was based on the concept of a similar intervention aimed at pervasive skills development, "The Amazing Tax Race”, which originated at the authors' employer university three years prior to hosting the intervention under review in this article. To enable presentation on a national level to students from various South African universities, the original concept was adjusted to the format of the national “Tax Amazing Race” (henceforth referred to as "the tax intervention”). Despite the fact that the main responsibility of planning, structuring and execution of the intervention rested with the authors, design variables and input were obtained from SAIT and various tax-related employers (including big four South African accounting, auditing and advisory firms) who developed and presented tax-related activities to participating teams. 
Although the integration of tax knowledge in these activities is important, the focus remained on the exposure to and development of pervasive skills. It is highlighted that the tax intervention did not impact the normal assessment of students at their respective universities and that participation in this extra-curricular activity was entirely voluntary.

Staying true to the action research process (Mills 2011), a pilot of the first two ever presented regional “Tax Amazing Races” were hosted in the year prior to the year in which data was formally collected for the evaluation of the intervention under review in this study. Personal field notes on effective and less effective elements pertaining to the overall planning, structure and execution of the pilot intervention were recorded to be reflected upon and for possible adjustments to be made for its repeat in the following year (Paisey and Paisey 2005).

Participation in the tax intervention occurred in university team context (each team comprising between six to ten members). The tax intervention comprised a race against time where teams had to visit numerous activity stations and theme park rides positioned across a theme park (situated either in the southern or northern region of South Africa) where tax-related activities had to be performed. The tax intervention commenced by awarding each team a theme park map and a clue leading teams to their first activity station. After successful completion of each specific tax activity, teams were awarded with an additional clue leading them to the next station. Teams moved between stations on a rotation basis and each race took between two and a half and three hours to complete. Six activities and four theme park rides were hosted in the southern region's intervention while seven activities and five theme park rides were hosted in the northern region, due to more teams entering in the northern region.

Activities hosted were designed to combine technical tax knowledge with the application and demonstration of pervasive skills in the form of innovative games. Gamification was applied to instil active learning (Ritzko and Robinson 2006) through the incorporation of a variety of experiential learning and active teaching methods. Clue cards were creatively formulated as tax riddles, tax-related crossword puzzles and tax calculations. Decryption of clues and execution of activities required students to apply leadership, effective communication and team work skills. Moreover, critical and strategic thinking had to be applied under time constraints (demonstrating time management skills as the intervention was a race against time) while interacting in a professional and ethical manner with staff from different employer companies manning the various activity stations.

\section{RESEARCH METHODOLOGY}

\section{Research paradigm, design and method}

Action research was performed within a positivistic paradigm where quantitative data was 
obtained through the use of questionnaires to survey student perceptions on the tax intervention hosted in both regions. Beylefeld (2005) describes action research as systematic cycles of thinking of what the researcher is busy with and what could be learnt from it. Students' perceptions were probed to evaluate the usefulness of tax intervention to develop pervasive skills. Datasets collected via questionnaires were supplemented by the field notes of the authors who critically observed and experienced the intervention during its initial pilot and its formal subsequent evaluation from one region to the next.

\section{The questionnaire}

The development of the questionnaire was based on a review of literature pertaining to teaching interventions aimed at the development of pervasive skills within the field of accounting education, the competency frameworks of various professional accounting bodies, and questionnaire design in general. An initial questionnaire was distributed during the pilot intervention in the previous year to ensure its validity and reliability (Smith 2011, 122) before it was subsequently used to formally survey the intervention under review in this article. Minor adjustments were made to the initial questionnaire before the distribution of the final questionnaire in the following year. The final questionnaire was also reviewed by one independent statistical consultant and three independent accounting education researchers to prevent unbiasedness and to ensure further validity and comprehensiveness.

The questionnaire consisted of eight subsections to capture the following data: demographical and profile information (Parts A and B); application (Part C) and exposure to pervasive skills (Part D); benefits and constraints of the intervention (Part E); as well as personal meaning gained, overall experience and participant recommendations (Parts F, G and $\mathrm{H})$. The questionnaire contained both Likert-type scale and open-ended questions. A four-point rating scale, where 1 = strongly disagree, 2 = disagree, 3 = agree and $4=$ strongly agree, was applied to all Likert-type questions as it is recommended by Berk (2014) to use even-numbered scales to determine teaching effectiveness.

\section{Collection, capturing and analysis of data}

The questionnaires were distributed to the participating students at the various universities for anonymous and voluntary completion shortly after each intervention was hosted. SPSS was used to conduct a principal factor analysis by using Oblimin rotation with Kaiser normalisation on the 20 items comprising "application of pervasive skills" and the 10 items comprising "exposure to pervasive skills", to explain the variance-covariance structure of variable set through a linear combination of these variables. To establish if the covariance matrix was 
suitable for factor analysis the Kaiser-Meyer-Olkin (KMO) measure of sampling adequacy was applied. Items with factor loadings below 0.3 were considered to be non-significant in correlation to its factors, while items with factor leadings in excess of 0.3 were considered to be contributing factors (Steyn 2000; Pallant 2013). Some factors were classified as factors with optimal interpretability as it cross-loaded on two factors where both factor loadings exceeded the 0.3 level. Cronbach's alpha-coefficient was computed as a reliability coefficient to confirm the internal consistency of each factor its Cronbach's alpha-coefficients were determined. For the purposes of this study all factors with a reliability coefficient above 0.6 were considered to be acceptable. The latter is based on the fact that Cortina (1993), Field $(2005,668)$ and Pallant (2013) all indicate that smaller Cronbach alpha coefficients will yield in instances where short scales are used. Hence, despite some Cronbach alpha coefficients found to be slightly below the norm of 0.7 , the authors still considered these components reliable based on its close proximity to the accepted norm. In addition, the inter-item correlation was also used as another measure of reliability that are expected to range between 0.15 and 0.55 at its acceptable level (Clark and Watson 1995).

Microsoft Excel was applied to capture and summarise data collected from open-ended questions for further scrutiny. Theory-building was enabled by relationships between data drawn from an emerging theme analysis.

\section{EMPIRICAL FINDINGS}

\section{Respondent profile}

The target population comprised 440 tax students (110 in the southern region; 330 in the northern region) from seven different universities across South Africa who had registered for the SAIT Tax Student Conferences. Overall, the sample population consisted of 218 tax students who participated in the tax intervention (11 teams in the southern region, comprising 100 students; and 14 teams in the northern region, comprising 118 students).

Although limited space for participation was available, tax students had an equal chance to enter as registration was completely voluntary. Entrants had to gain access for participation by means of a web-based registration process functioning on a first-come-first-serve basis prior to the conference. Consequently the target population represented an availability samples rather than a random sample. A total of 164 completed questionnaires were collected (response rate of $75 \%$ ) of which 72 were from the southern region (response rate of $72 \%$ ) and 92 from the northern region (response rate of $78 \%$ ) (see table 1 ). 
Table 1: Regional profile of respondents

\begin{tabular}{|c|c|c|c|c|}
\hline University & $\begin{array}{l}\text { Number of } \\
\text { respondents } \\
\text { per university }\end{array}$ & $\begin{array}{c}\text { Southern region } \\
\% \\
\mathrm{~N}=72 \\
\end{array}$ & $\begin{array}{c}\text { Northern region } \\
\% \\
\mathrm{~N}=92 \\
\end{array}$ & $\begin{array}{c}\begin{array}{c}\text { Overall } \\
\% \\
\mathrm{~N}=164\end{array} \\
\end{array}$ \\
\hline S1 & 30 & 41.7 & - & 18.3 \\
\hline $\mathrm{S} 2$ & 23 & 31.9 & - & 14.0 \\
\hline S3 & 19 & 26.4 & - & 11.6 \\
\hline N1 & 28 & - & 30.4 & 17.1 \\
\hline N2 & 27 & - & 29.3 & 16.5 \\
\hline N3 & 27 & - & 29.3 & 16.5 \\
\hline N4 & 10 & - & 11.0 & 6.0 \\
\hline Total & 164 & 100 & 100 & 100 \\
\hline
\end{tabular}

Source: Viviers 2016

Table 2: Demographic profile of the study population

\begin{tabular}{|l|c|c|c|}
\hline \multicolumn{1}{|c|}{ Variable } & $\begin{array}{c}\text { Southern } \\
\text { region } \\
\% \\
\mathbf{N = 7 2}\end{array}$ & $\begin{array}{c}\text { Northern } \\
\text { region } \\
\% \\
\mathbf{N}=92\end{array}$ & $\begin{array}{c}\text { Overall } \\
\text { \% }\end{array}$ \\
$\mathbf{N = 1 6 4}$ \\
\hline Gender: & & & \\
\hline Female & 54.2 & 59.8 & 57.3 \\
\hline Male & 45.8 & 40.8 & 42.7 \\
\hline Racelethnic group: & & & \\
\hline African/Black & 37.5 & 55.4 & 47.5 \\
\hline Brown/Coloured & 43.1 & 6.5 & 22.6 \\
\hline Asian/Indian & 8.3 & 3.3 & 5.5 \\
\hline White & 8.3 & 34.8 & 23.2 \\
\hline Other & 2.8 & - & 1.2 \\
\hline Degree/Qualification registered for: & & & \\
\hline BCom Chartered Accountancy (3 ${ }^{\text {rd }}$ year) [SAICA] & 5.6 & 4.4 & 4.9 \\
\hline Hons BCom Chartered Accountancy / CTA [SAICA] & 41.6 & 30.4 & 35.4 \\
\hline BCom Financial Accounting (3rd year) [SAIPA/CIMA] & 1.4 & 2.2 & 1.8 \\
\hline Hons BCom Financial Accountancy [SAIPA/CIMA] & - & 4.3 & 2.4 \\
\hline BCom Taxation [SAIT] & 2.8 & 4.3 & 3.7 \\
\hline Hons BCom Taxation [SAIT] & 11.1 & 44.6 & 29.8 \\
\hline Other (including second year and BCom LLB students) & 37.5 & 9.8 & 22.0 \\
\hline
\end{tabular}

Source: Viviers 2016

The study population comprised a good coverage of tax students enrolled for a variety of accounting degree programmes at seven different higher education institutions accredited by various professional accounting bodies. The majority $(65.2 \%)$ of the study population comprised honours-level students who had already been exposed to and passed undergraduate tax modules. The latter profile reduces the possibility of biased results as responses were obtained from students with various backgrounds and geographical origin.

\section{Results of the factor analysis: Application of pervasive skills}

The datasets for the intervention in both regions (southern and northern) were combined for the performance of an exploratory factor analysis. The analysis yielded a KMO value of 0.85 proving appropriate factorability as it exceeded the recommended value of 0.6. Statistical 
significance was also achieved with the Bartlett's Test of Sphericity (BTS) value of 0.00, which was below the required 5 per cent level (Pallant 2013, 190). Overall, factor loadings were relatively high and a strong correlation was identified between the factors and their component items as all items loaded on a factor with a loading above 0.3. From the factor analysis performed, four factors were extracted (see table 3) from the data regarding the 20 items resonated under the section "during my participation in the tax intervention I had to do or use the following”. These four factors were labelled as: Leadership (Factor 1); Influencing others (Factor 2); Strategic and critical thinking (Factor 3); and Communication (Factor 4). All factors (except Factor 2) had a Cronbach's alpha-coefficient ranging between 0.67 and 0.80, which confirmed the reliability of the dataset (Field 2005). As factor 2 only consisted of two items, its inter-item correlation was considered to be a stronger indicator of reliability (Clark and Watson 1995) and was calculated as 0.38 (falling within the acceptable range of 0.15 to 0.55 ).

Table 3: Factor analysis (Application of pervasive skills)

\begin{tabular}{|c|c|c|c|c|}
\hline Application factors and items & 1 & 2 & 3 & 4 \\
\hline \multicolumn{5}{|l|}{ Factor 1: Leadership } \\
\hline Taking lead (I directed my team on what to do) & 0.784 & & & \\
\hline I had to motivate others & 0.760 & & & \\
\hline Being a team player (contributing to the team's success) & 0.740 & & & \\
\hline Thinking on my feet / Making quick decisions & 0.520 & & & \\
\hline I had to function effectively within a group (team work) & 0.430 & & & \\
\hline Being a listener (I had to listen to opinions of team members) & 0.429 & & & \\
\hline I performed time management as it was a race against time & 0.403 & & & \\
\hline I had to adapt to change and unexpected events & 0.398 & & & \\
\hline $\begin{array}{l}\text { I thought differently about academic concepts due to being forced } \\
\text { to think creatively }\end{array}$ & 0.345 & & & \\
\hline \multicolumn{5}{|l|}{ Factor 2: Influencing others } \\
\hline $\begin{array}{l}\text { Ability to persuade others (I had to take a stand to convince my } \\
\text { team members of facts and theory application) }\end{array}$ & & 0.632 & & \\
\hline I had to express my opinion/understanding of a concept & & 0.498 & & \\
\hline \multicolumn{5}{|l|}{ Factor 3: Strategic and critical thinking } \\
\hline I learned from the way team members interpreted concepts & & & 0.307 & \\
\hline I had to motivate myself to stay involved and to participate & & & 0.878 & \\
\hline I had to manage myself to contribute to success of my team & & & 0.709 & \\
\hline I had to apply critical thinking skills to solve problems & & & 0.433 & \\
\hline I had to apply theoretical concepts practically & & & 0.348 & \\
\hline \multicolumn{5}{|l|}{ Factor 4: Communication } \\
\hline $\begin{array}{l}\text { I had to demonstrate my analytical ability by forming logical } \\
\text { arguments and summarising information }\end{array}$ & & & & 0.750 \\
\hline I had to execute strategies for the task at hand & & & & 0.749 \\
\hline I acted in an ethical manner (keeping to the rules of the race) & & & & 0.712 \\
\hline I had to communicate my ideas and opinions to others & & & & 0.410 \\
\hline Total variance explained & $50 \%$ & & & \\
\hline Cronbach's alpha-coefficient & 0.80 & 0.55 & 0.67 & 0.69 \\
\hline Inter-item correlation & 0.32 & 0.38 & 0.30 & 0.35 \\
\hline Mean value & 3.36 & 3.28 & 3.27 & 3.38 \\
\hline
\end{tabular}

Source: Viviers 2016

Factor scores were computed as the average of all items (underlying actions representing skills applied) contributing to a specific factor (specific pervasive skill) in order to interpret it on the 
original four-point Likert scale. Table 3 indicates that Communication (Factor 4) yielded the highest mean value (3.38), thus representing the main pervasive skill that students had to apply during participation in the tax intervention, followed by Leadership (Factor 1; 3.36), Influencing others (Factor 2; 3.28) and Strategic and critical thinking (Factor 3; 3.27).

\section{Results of the factor analysis: Exposure to pervasive skills}

The datasets of both regions were again combined for the analysis. With a KMO value of 0.82 the factorability of the data grouping was confirmed (it exceeded the minimum value of 0.6) and a BTS value of 0.00 (which was under the required 5 per cent level) (Pallant 2013, 190). From the 10 items (pervasive skills required by professional bodies) resorting under the section "the intervention exposed me to the following pervasive skills" two factors were extracted (see table 4). The two factors were labelled as: Inter-personal skills (Factor 1); and Personal skills (Factor 2). The data was considered to be reliable since the Cronbach's alpha-coefficient for both the factors yielded a value of 0.77 (Field 2005), while the inter-item correlation was 0.6 (Factor 1) and 0.47 (Factor 2).

Table 4: Factor analysis (Exposure to pervasive skills)

\begin{tabular}{|l|c|c|}
\hline Exposure factors and items & $\mathbf{1}$ & $\mathbf{2}$ \\
\hline Factor 1: Inter-personal skills & & \\
\hline Leadership & 0.841 & \\
\hline Professionalism & 0.708 & \\
\hline Ethical awareness & 0.640 & \\
\hline Strategy & 0.635 & \\
\hline Critical thinking & 0.560 & \\
\hline Influencing others & 0.552 & \\
\hline Factor 2: Personal skills & & \\
\hline Team work & & 0.851 \\
\hline Problem solving & & 0.825 \\
\hline Communication (verbal and listening) & 0.753 \\
\hline Time management & & 0.599 \\
\hline Total variance explained & $53 \%$ & \\
\hline Cronbach's alpha-coefficient & 0.77 & 0.77 \\
\hline Inter-item correlation & 0.36 & 0.47 \\
\hline Mean value & 3.42 & 3.62 \\
\hline
\end{tabular}

Source: Viviers 2016

"Inter-personal skills" are defined as the capacity to project oneself into the inner experience of another human being (Dean 1984, 130). The notion encapsulates skills contributing towards the achievement of a group dynamic. Skills resorting under Factor 1 (“Inter-personal skills”) include taking lead, acting ethically and professionally, and demonstrating strategy by thinking critically and influencing others. "Personal skills", on the other hand, are described as communication skills, initiative, creativity, the capacity to solve problems (Stewart and Knowles 2001) and also the ability to work well with others, to organise and self-motivation 
(DfEE 1997, 34). Items resorting under Factor 2 (“Personal skills”) are the pervasive skills participants were exposed to and which they applied in conducting themselves. This skill comprised contributing as an individual team player (team work), solving problems, sharing personal ideas verbally and listening to others (effective communication), as well as successful time management. The average mean score for both the inter-personal skills (3.42) and the personal skills (3.62) was high and reached a value very close to 4 (representing "Strongly agree”), serving as proof that the tax intervention was indeed perceived to be successful in exposing students to both the inter-personal and personal skills (i.e. the pervasive skills) required by professional bodies as identified from the literature review (refer to section 3.1).

\section{Main perceived benefit of the tax intervention}

The questionnaire posed an open-ended question to respondents requiring them to list, based on their perceptions, all possible benefits linked to their participation in the tax intervention. Answers to this question was analysed and (as far as possible) grouped and labelled in pervasive skills development benefit themes (see table 5).

Table 5: Main perceived benefits of the tax intervention

\begin{tabular}{|l|c|c|c|}
\hline \multicolumn{1}{|c|}{ Benefit themes } & $\begin{array}{c}\text { Southern } \\
\text { region } \\
\text { \% } \\
(\mathbf{N = 7 2 )}\end{array}$ & $\begin{array}{c}\text { Northern } \\
\text { region } \\
\text { \% } \\
\mathbf{( N = 9 2 )}\end{array}$ & $\begin{array}{c}\text { Overall } \\
\text { (N=164) }\end{array}$ \\
\hline Team work skills development & 23.6 & 16.3 & 19.5 \\
\hline Learning by having fun & 11.1 & 19.6 & 15.9 \\
\hline Obtaining a holistic view of the tax profession & 15.2 & 6.5 & 10.4 \\
\hline Creates a network opportunity & 8.3 & 9.8 & 9.1 \\
\hline $\begin{array}{l}\text { Integrated learning opportunity combining technical and soft skills } \\
\text { development in a tax-related environment }\end{array}$ & 9.7 & 7.6 & 8.5 \\
\hline Development of social skills / inter-personal skills & 9.7 & 7.6 & 8.5 \\
\hline Better understanding of tax theory due to practical application & 2.8 & 9.8 & 6.7 \\
\hline Personal attributes: enhance self-confidence & 2.8 & 7.6 & 5.5 \\
\hline New way of learning & 4.2 & 6.5 & 5.5 \\
\hline Time management skills development & 1.4 & 6.5 & 4.3 \\
\hline Communication skills development & 4.2 & 1.1 & 2.4 \\
\hline
\end{tabular}

(Some respondents indicated more than one/ no benefit; thus, the totals could exceed/be below 100\%)

Source: Viviers 2016

The greatest benefit of the tax intervention was perceived to be team work skills. Despite the fact that the development of pervasive skills was the main focus of this article, the results clearly indicate that participants also perceived the tax intervention to be largely beneficial in that it was experienced to be a fun way of learning and a good method of obtaining a better understanding and a holistic view of the tax profession. Because students were required to apply their tax knowledge practically and obtained a better understanding of tax theory and concepts, it serves as proof that the tax intervention also positively contributed towards the development of technical skills. 


\section{Main perceived constraints of the tax intervention}

Students were required to indicate the negative aspects and possible constraints experienced during their participation in the tax intervention. Table 6 presents the findings of this openended question.

Table 6: Main perceived constraints of the tax intervention

\begin{tabular}{|l|c|c|c|}
\hline \multicolumn{1}{|c|}{ Constraint themes } & $\begin{array}{c}\text { Southern region } \\
\text { \% } \\
(\mathbf{N = 7 2 )}\end{array}$ & $\begin{array}{c}\text { Northern region } \\
\text { \% } \\
\mathbf{( N = 9 2 )}\end{array}$ & $\begin{array}{c}\text { Overall } \\
\text { \% } \\
(\mathbf{N = 1 6 4 )}\end{array}$ \\
\hline Time management & 12.5 & 8.7 & 10.4 \\
\hline Physical aspects / fitness level & 13.9 & 6.5 & 9.8 \\
\hline Difficulty level & 12.5 & 4.3 & 7.9 \\
\hline Conflict within teams & 1.4 & 4.3 & 3.0 \\
\hline Competitive advantage & 2.8 & 3.3 & 3.0 \\
\hline Limited space for participation & 2.8 & 2.2 & 2.4 \\
\hline Group composition/team size & 1.4 & 3.3 & 2.4 \\
\hline Limited networking opportunity & 1.4 & 1.1 & 1.2 \\
\hline
\end{tabular}

(Some respondents reported no constraints, thus totals per region and overall are less than 100\%)

Source: Viviers 2016

The ability to demonstrate effective time management skills during participation was found to be the main constraint. Respondents indicated that the intervention was physically challenging and that they struggled to keep up in the race against time. Participants realised that they were unfit and found themselves to be tired and ultimately exhausted. Despite the fact that the majority of participants were honours-level students (see table 2 for demographic profile), thus constituting respondents who already passed their undergraduate taxation modules, some participants experienced the level of difficulty for some of the activities to be quite high. Some tax topics were highlighted as not yet covered at their specific academic level. However, because far less constraints than benefits were reported, it could be concluded that overall, the tax intervention was experienced far more positively than negatively and that it benefited the participants in various aspects.

\section{Overall experience and recommendation of tax intervention as an effective method to develop pervasive skills}

Participants were requested to provide a single word to describe their overall experience of the tax intervention. Table 7 indicates the frequency distribution of the single word analysis and shows that the tax intervention was majorly described (in both regions) through the use of positive words. In total, 40 different positive words were used to describe the tax intervention, compared to only five negative and 2 neutral words. The three words: “amazing”, "awesome” 
and "fun", were used most frequently. Other positive adjectives that were used more than three times included: “educational”, “exciting”, “fantastic”, “informative”, “inspirational”, “interesting” and "motivating”.

Table 7: Frequency distribution of single word descriptions

\begin{tabular}{|l|c|c|c|}
\hline Type of one-word description used & $\begin{array}{c}\text { Southern region } \\
\mathbf{\%} \\
\mathbf{( N = 7 2 )}\end{array}$ & $\begin{array}{c}\text { Northern region } \\
\mathbf{\%} \\
\mathbf{( N = 9 2 )}\end{array}$ & $\begin{array}{c}\text { Overall } \\
\mathbf{\%} \\
\mathbf{( N = 1 6 4 )}\end{array}$ \\
\hline Positive & 87.2 & 90.2 & 89.0 \\
\hline Negative & 1.4 & 4.3 & 3.0 \\
\hline Neutral & - & 2.2 & 1.2 \\
\hline No response & 11.1 & 3.3 & 6.7 \\
\hline
\end{tabular}

Source: Viviers 2016

Overall, only five respondents (one from the southern region and four from the northern region) described the tax intervention using negative words, namely "long” (southern region) and “unfair”, “exhausting”, “tough” and “mediocre” (northern region). Although the negative descriptions are not considered to be significant in comparison to the large number of positive descriptions, the negative responses (four) could possibly be ascribed to the negative weather conditions (rain) that affected the intervention in the northern region compared to the single negative description raised in the southern region. Rain conditions near the end of the race in the northern region necessitated some of the theme park rides to close due to safety reasons, prohibiting some participants in completing these rides. These participants might have felt aggrieved in forfeiting the opportunity to experience these rides, which could have resulted in the negative one-word descriptions such as "mediocre” and “unfair”. From all responses, only two neutral words were used to describe the tax intervention. These were "rush", which could either be interpreted as positive (experiencing an adrenaline rush), or negative (in that the intervention itself was too rushed), and "experience” which could also have been positive or negative.

Words that supported the tax intervention's educational value and its ability to develop pervasive skills and personal attributes comprised: "beneficial”, “challenging”, “clarifying”, “critical-thinking”, “enlightening”, "happiness", “insightful” and "worth-it”. The fresh and innovative nature of the tax intervention were echoed by words such as "adventurous", “awakening”, “entertaining”, “exceptional”, “exhilarating”, “innovative”, “superb” and “world-class".

Table 8 indicates the extent to which participants within each region would recommend the tax intervention under review in this study, as well as similar interventions, to other tax students as a vehicle to promote the development of pervasive skills as part of their higher education and training. 
Table 8: Comparison on overall recommendation of the tax intervention (t-test)

\begin{tabular}{|c|c|c|c|c|c|c|}
\hline \multirow[t]{2}{*}{ Variable } & \multicolumn{2}{|c|}{$\begin{array}{l}\text { Southern } \\
\text { region } \\
(\mathrm{N}=72)\end{array}$} & \multicolumn{2}{|c|}{$\begin{array}{l}\text { Northern } \\
\text { region } \\
(\mathrm{N}=92)\end{array}$} & \multirow[t]{2}{*}{$p$-value* } & \multirow{2}{*}{$\begin{array}{l}\text { Effect size } \\
(d-\text {-value })^{\wedge}\end{array}$} \\
\hline & $\begin{array}{l}\text { Mean } \\
(1-4)\end{array}$ & $\begin{array}{l}\text { Std } \\
\text { dev. }\end{array}$ & $\begin{array}{c}\text { Mean } \\
(1-4)\end{array}$ & $\begin{array}{l}\text { Std } \\
\text { dev. }\end{array}$ & & \\
\hline $\begin{array}{l}\text { I would recommend participation in the tax } \\
\text { intervention to other students }\end{array}$ & 3.70 & 0.46 & 3.85 & 0.47 & 0.04 & 0.32 \\
\hline $\begin{array}{l}\text { I would recommend teaching methods similar } \\
\text { the tax intervention to be hosted at my } \\
\text { university in order to develop my pervasive } \\
\text { skills }\end{array}$ & 3.57 & 0.61 & 3.75 & 0.51 & 0.04 & 0.31 \\
\hline
\end{tabular}

Source: Viviers 2016

Despite the fact no significant differences were identified in the mean scores between the two regions, it is evident that the mean scores were all found to be close to 4 (representing "Strongly agree”). The latter serves as a clear indication that the tax intervention was positively perceived to be useful in the development of pervasive skills.

\section{FINDINGS, CONCLUSIONS AND RECOMMENDATIONS}

This is the first study of its kind to explore and evaluate the usefulness of a tax intervention presented on a national level and aimed at the development of pervasive skills amongst tax students at the higher education level across South African universities. Based on the findings (as presented in Sections 6.2 and 6.3) the tax intervention was perceived to be successful in encouraging tax students to apply the pervasive skills of: leadership, influencing others, strategic and critical thinking, and communication. In addition, it is concluded that the tax intervention succeeded to expose tax students to both the personal and inter-personal skills set encapsulating all ten required pervasive skills as identified from the review of competency frameworks of the professional accounting bodies responsible for accrediting accountingrelated degree programmes that tax students are enrolled for at South African universities.

The main benefits associated with the tax intervention were perceived to be the development of team work skills, to learn while having fun, to obtain a better understanding of tax concepts due to an integrated learning opportunity where the application of technical and soft skills are combined, in enhancing self-confidence and positively contributes to relationship building. However, participants perceived the main constraints of the tax intervention for it to be very exhausting and physically challenging, and that the difficulty level of the activities was in some instances too high.

To enhance student engagement that will promote the application of a wider range of the required pervasive skills set and to enable the application of tax knowledge on a more 
accommodating difficulty level, it is recommended that the organisers of the intervention should liaise more closely with professional accounting bodies and employer firms regarding the overall planning of such intervention. The latter will better inform organising stakeholders as to the appropriate level of difficulty at which activities should be designed for it to be more closely aligned with students' level of understanding of tax concepts.

Overall, the tax intervention was perceived to be successful and positively experienced in contributing towards the application and development of pervasive skills. The development, design and execution of interventions has been reported to be very time-consuming. Therefore, national-based interventions that are able to accommodate large numbers of participants from a wide spectrum of students across the country is regarded to be beneficial in that it releases pressure from individual higher education tax educators to develop and present their own interventions at their respective individual universities.

This article provides new insights regarding students' perceptions on the use of a nationally hosted tax-related intervention as a teaching tool to develop pervasive skills in tax students in preparing them for the formal workplace. Further research suggestions include the evaluation of (as part of the continuing cycles of the action research process) the usefulness of nationally hosted interventions from the perspectives of professional bodies and employer firms involved, as well as that of tax educators and trainers at the higher education level.

\section{LIMITATIONS OF THE STUDY}

As pervasive skills are intangible and inherently embedded within one's true personality, human nature and ability, it makes it difficult to measure and assess with precision. Thus, although the research explored the tax intervention's ability to expose tax students to and encouraged them to apply pervasive skills, it did not measure the actual benefit derived. Positive responses could be limited due to the fact that some students only participated for the enjoyable experience and entertainment value (games and theme park rides) associated with this type of intervention. However, although it remains a challenge to create a tax-related environment that simulates the real tax world in which pervasive skills need to be applied, the tax intervention in this research succeeded in providing a fun and creative environment where tax students were encouraged to apply and be exposed to opportunities in which to develop pervasive skills.

\section{REFERENCES}

ACCA, see Association of Chartered Certified Accountants.

Association of Chartered Certified Accountants. 2015. P6 Advanced Taxation South Africa (ZAF) syllabus and study guide 2016. http://www.accaglobal.com/za/en/student/exam-supportresources/professional-exams-study-resources/p6/syllabus-study-guide/p6-syllabus-and-study- 
guide-south-africa-zaf.html (Accessed 30 December 2015).

Ballantine, J. and P. McCourt Larres. 2009. Accounting undergraduates' perceptions of cooperative learning as a model for enhancing their interpersonal and communication skills to interface successfully with professional accountancy education and training. Accounting Education: An International Journal 18(4-5): 387-402.

Barrie, S. C. 2004. A research-based approach to generic attributes policy. Higher Education Research and Development 23(3): 261-275.

Bennett, R. 2002. Employers' demands for personal transferable skills in graduates: A content analysis of 1000 job advertisements and an associated empirical study. Journal of Vocational Education \& Training 54(4): 457-476.

Berk, R. A. 2014. Top 10 flashpoints in student ratings and the evaluation of teaching: What faculty and administrators must know to protect themselves in employment decisions. Sterling: Stylus Publishing.

Beylefeld, A. A. 2005. The challenge of creating knowledge through action research. South African Journal of Higher Education 19(1): 1321-1333.

Burns, A. C. and J. W. Gentry. 1998. Motivating students to engage in experiential learning: A case study. Simulation and Gaming 29(2): 133-151.

CGMA, see Chartered Global Management Accountant.

Chartered Global Management Accountant. 2014. CGMA Competency Framework Overview Brochure.

Chartered Institute of Management Accountants. 2015. CIMA Competency Framework. http://www. cimaglobal.com/Students/Exam-resources-and-information/Qualifications/Competency-frame work-and-employability/ (Accessed 29 December 2015).

CIMA, see Chartered Institute of Management Accountants.

Clark, L. A. and D. Watson. 1995. Constructing validity: Basic issues in objective scale development. Psychological Assessment 7(3): 309-319.

Cortina, J. M. 1993. What is coefficient alpha? An examination of theory and applications. Journal of Applied Psychology 78: 98-104.

Dean, R. G. 1984. The role of empathy in supervision. Clinical Social Work Journal 12(2): 129-139.

Department for Education and Employment. 1997. Labour Market Skills and Trends 1997/98. London: DfEE.

DfEE, see Department for Education and Employment.

De Villiers, R. 2010. The incorporation of soft skills into accounting curricula: preparing accounting graduates for their unpredictable futures. Meditari Accountancy Research 18(2): 1-22.

De Villiers, R. R. and J. P. Fouché. 2015. The effectiveness of the teaching methodologies in audit education: A student perspective. South African Journal of Higher Education 29(6): 58-77.

Dewey, J. 1938. Experience and education. Collier Books: New York, NY.

Field, A. 2005. Discovering statistics using SPSS. London: SAGE publications.

Fouché, J. P. 2013. A renewed call for change in accounting education practices. International Journal of Education Sciences 5(2): 137-150.

Gammie, B., E. Gammie and E. Cargill. 2002. Personal skills development in the accounting curriculum. Accounting Education: An International Journal 11(1): 63-78.

Hannon, S., H. McBride and B. Burns. 2004. Developing creative and thinking abilities in business graduates: The value of experiential learning. Industry and Higher Education (18)2: 95-100.

Hassall, T., J. Joyce, J. Montanto and J. Anes. 2005. Priorities for the development of vocational skills in management accountants: A European perspective. Accounting Forum 29(4): 379-394.

Jackson, D. and E. Chapman. 2012. Non-technical skills gaps in Australian business graduates. Education \& Training 54(23): 95-113. 
Jackson, D., R. Sibson and L. Riebe. 2013. Undergraduate perceptions of the development of teamworking skills. Education \& Training 56(1): 7-20.

Kermis, G. and M. Kermis. 2010. Professional presence and soft skills: A role for accounting education. Journal of Instructional Pedagogies 2: 1-10.

Kolb, A. Y. and D. A. Kolb. 2005. Learning styles and learning spaces: enhancing experiential learning in higher education. Academy of Management Learning and Education 4(2): 193-212.

Mills, G. E. 2011. Action research: A guide for the teacher researcher. $4^{\text {th }}$ Edition. Boston: Pearson.

Paisey, C. and N. J. Paisey. 2005. Improving accounting education through the use of action research. Journal of Accounting Education 23(2005): 1-19.

Pallant, J. 2013. SPSS survival manual. $5^{\text {th }}$ Edition. Berkshire, UK: McGraw-Hill. Open University Press.

Ramlall, S. and D. Ramlall. 2014. The value of soft-skills in the accounting profession: Perspectives of current accounting students. Advances in Research 2(11): 645-654.

Ritzko, J. M. and S. Robinson. 2006. Using games to increase active learning. Journal of College Teaching \& Learning 3(6): 45-50.

Rudman, R. J. and W. Kruger-van Renen. 2014. South African students' perceptions of the usefulness of a management accounting simulation. Journal of Economic and Financial Sciences 7(1): 187212.

Rudman, R. J. and J. Terblanche. 2011. Practical role-play as an extension to theoretical audit education: A conceptualising aid. Southern African Journal of Accountability and Auditing Research 11(2011): 63-74.

SAICA, see South African Institute of Chartered Accountants.

Smith, M. 2011. Research methods in accounting. $2^{\text {nd }}$ Edition. London: Sage Publications.

South African Institute of Chartered Accountants. 2016. Competency framework detailed guidance for academic programmes: Competencies of a CA(SA) at the point of the Initial Test of Competence (ITC) (assessment of core technical knowledge). Johannesburg: SAICA.

Stainbank. L. 2009. Working in teams; improving the team experience. Meditari Accountancy Research 17(1): 69-80.

Steenkamp, G. 2012. Students' perceptions regarding the new training programme for chartered accountants. Journal of Economic and Financial Sciences 5(2): 481-498.

Stewart, J. and V. Knowles. 2001. Graduate recruitment: Implications for business and management courses in HE. Journal of European Industrial Training 25(2/3/4): 98-108.

Steyn, H. S. 2000. Practical significance of the difference in means. South African Journal of Industrial Psychology 26(3): 1-3.

Strauss-Keevy, M. 2014. Education programmes responsibilities regarding pervasive skills. Journal of Economic and Financial Sciences 7(2): 415-432.

Strauss-Keevy, M. 2015. Using collaborative learning excercises to transfer pervasive skills: Some South African evidence. Journal of Economic and Financial Sciences 8(2): 456-473.

Van der Merwe, N. 2013. An evaluation of an integrated case study and business simulation to develop professional skills in South African accountancy students. International Business and Economics Research Journal 12(10): 1137-1156.

Viviers, H. A. 2016. Developing a teaching intervention to expose accounting students to pervasive skills. North-West University Potchefstroom Campus. Thesis - Ph.D.

Yan, F. M. 1999. Experiential learning: Functional attributes and effectiveness. Studies in Continuing Education 21(1): 57-72. 